\title{
A study of functional outcome in intertrochanteric femur fractures treated by proximal femoral nailing
}

\author{
Khairnar $\mathbf{A}^{1}$, Patil $\mathbf{L}^{2}$ \\ ${ }^{1}$ Dr. Amol Khairnar, Assistant Professor, Department of Orthopedics, S.B.H. GMC, Dhule, Maharashtra, India, \\ ${ }^{2}$ Dr. Lalit Patil, Ex. Assistant Professor; Department of Orthopedics, S.B.H. GMC, Dhule, Maharashtra, India.
}

Corresponding Author: Dr. Amol Khairnar, Assistant Professor, Department of Orthopedics, S.B.H. GMC, Dhule, Maharashtra, India. E-mail: amolkortho@gmail.com

\begin{abstract}
Introduction: Intertrochanteric femur fracture is one of the most common fractures of the hip especially in the elderly with osteoporotic bones, usually due to trivial trauma. Dynamic Hip Screw (DHS) is still considered the gold standard for treating intertrochanteric fractures by many. Proximal femoral nail is a relatively newer implant designed to treat unstable intertrochanteric fractures. The present study was conducted to evaluate functional outcome in intertrochanteric femur fractures treated by proximal femoral nailing. Methods: The present study is a prospective study performed on 98 patients of intertrochanteric femoral fractures treated by Proximal Femoral Nail (PFN) in department of Orthopedics at Shri Bhausaheb Hire Government Medical College, Dhule. Functional outcome was assessed by modified Harris hip score at the end of 6 months postoperatively. Result: Total 98 patients were included, 32 were females and 66 were males. Age group ranged from 18 to 85 years. Maximum patients (40.81\%) were between 60 to 70 yrs age group. 56.12\% of patients had Evans type I fracture and the rest (43.87\%) had type II fracture. Excellent outcome observed in $30.6 \%$ patients, good in $44.9 \%$, fair outcome in $14.2 \%$ and only $10.2 \%$ had poor outcome among 98 patients. Conclusion: It is concluded from our study that use of PFN for treatment of intertrochanteric fractures provides a good functional outcome along with advantages in terms ofminimal blood loss, early weight bearing and few complications. It is the implant of choice for unstable intertronchanteric fractures.
\end{abstract}

Keywords: Proximal femoral nail, Intertrochanteric fractures, Proximal femur fracture.

\section{Introduction}

Intertrochanteric femur fracture is one of the most common fractures of the hip especially in the elderly with osteoporotic bones, usually due to trivial trauma.

Age of patient, osteoporosis, general health, associated co-morbidities are some of the key factors to be considered for the successful treatment of these fractures [1,2].

Various types of implants are available for fixation. The ideal internal fixation device should be such that the patient can be mobilized at the earliest without jeopardizing the reduction, stability and union of the fracture. Recently intramedullary fixation devices have become increasingly popular because of its biomechanical advantage. The proximal femoral nail

Manuscript received: $10^{\text {th }}$ August 2018

Reviewed: $20^{\text {th }}$ August 2018

Author Corrected: $28^{\text {th }}$ August 2018

Accepted for Publication: $31^{\text {st }}$ August 2018
(PFN) is one of such implants which was developed by the AO/ASIF in 1996 [3]. The main principle of this type of fixation is based on a sliding screw in the femoral neck-head fragment, attached to an intramedullary nail and this acts as a load sharing device unlike DHS which is load bearing device.

Hence PFN i.e. intramedullary fixation device is biomechanically stronger implant.

Despite being technically demanding surgical procedure these implants are gaining wide acceptance in treating unstable intertrochanteric fractures because of its advantages of being inserted through small exposure, preservation of hematoma and less blood loss $[4,5]$.

Considering the advantages of PFN the present study was carried out to know the functional outcome of the patients treated by the same. 


\section{Materials and Methods}

The present study is a prospective non-controlled, non-randomized, non-blinded study conducted at the Department of Orthopaedics, Shri Bhausaheb Hire Government Medical College, Dhule from Jan 2014 to Dec 2016.

Inclusion Criteria- Total 98 patients of intertrochanteric fractures which were admitted in the outpatient and emergency department of orthopaedicswere included in the study. Patients of either sex and closed fractures were included.

Exclusion Criteria-1. Pathological fractures. 2. Polytrauma. 3. Patients with co-morbid conditions like stroke that may hinder rehabilitation

Radiological confirmation of the diagnosis was carried out by taking anterior-posterior x-rays of hip and the fractures were classified according to Evans and AO/OTA Classification, unstable varieties include 31 A2.2 to 31A3.3 [6]. All patients were treated by proximal femoral nail. Intertrochanteric fractures were treated by closed reduction and internal fixation on a fracture table using a proximal femoral nail (PFN) under $\mathrm{C}$ arm guidance.

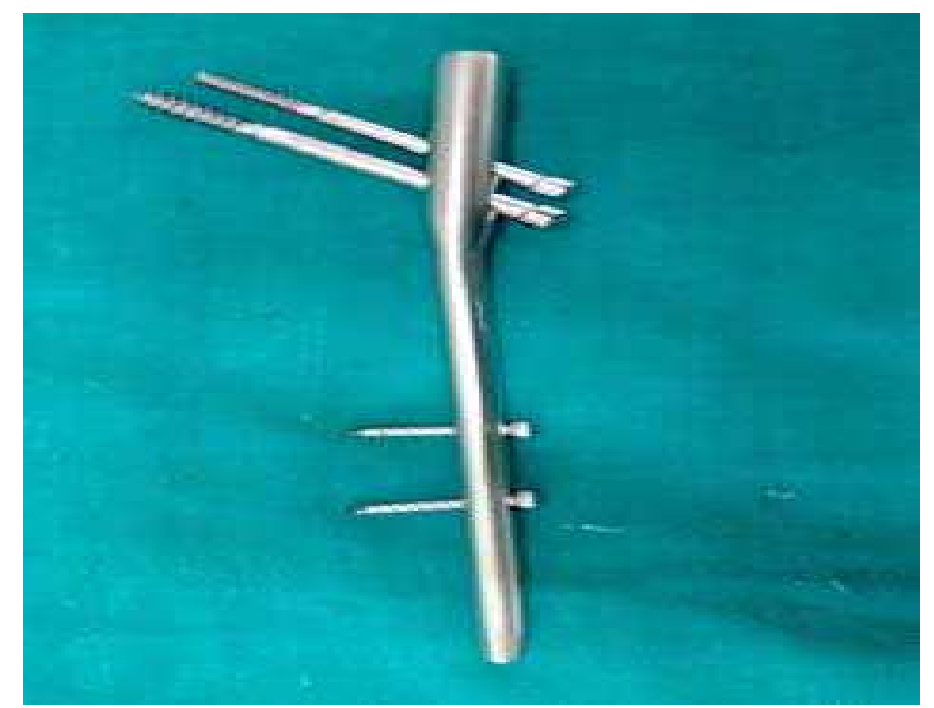

Proximal femoral nail (PFN) of basic design invented by AO having $8 \mathrm{~mm}$ lag screw, $6.4 \mathrm{~mm}$ derotation neck screw, 4.9 $\mathrm{mm}$ distal interlocking bolts were used. Intraoperative data (type of reduction, closed reduction, duration of surgery and intra-operative complication) were recorded.

Parenteral antibiotics, usually third generation cephalosporin were started immediately after the admission and postoperatively. Static quadriceps exercises were encouraged from the first day and the knee was mobilized from the third day. Patients were followed up at $2^{\text {nd }}, 6^{\text {th }}$ and $12^{\text {th }}$ week postoperatively. After 6 months the functional outcome of the patient was assessed using modified Harris Hip score [7].

Radiological assessment for progression and time of union, fracture alignment and implant related complications were analysed. Data collected at the end of the study was statistically analysed. Pain and functional capacity are the two basic considerations for this scoring system. Points are given for pain, function, range of motion and absence of deformity.

Harris hip score was collected using a pre-designed Performa by the principal investigator. Confounding variables as well as bias was controlled by strictly following the exclusion criteria. Data were entered and analyzed through Statistical Package for Social Sciences (V-17).

Mean and standard deviation were computed for the quantitative variable i.e., age. Frequency and percentage were calculated for qualitative variables like gender, mode of admission, type of fracture, and functional outcome (Excellent to poor). Effect modifiers were controlled by stratification of age, gender, type of fracture and mode of admission to observe the effect of these modifiers on outcome by using chi square test and $p$ value $\leq 0.05$ was considered significant. 


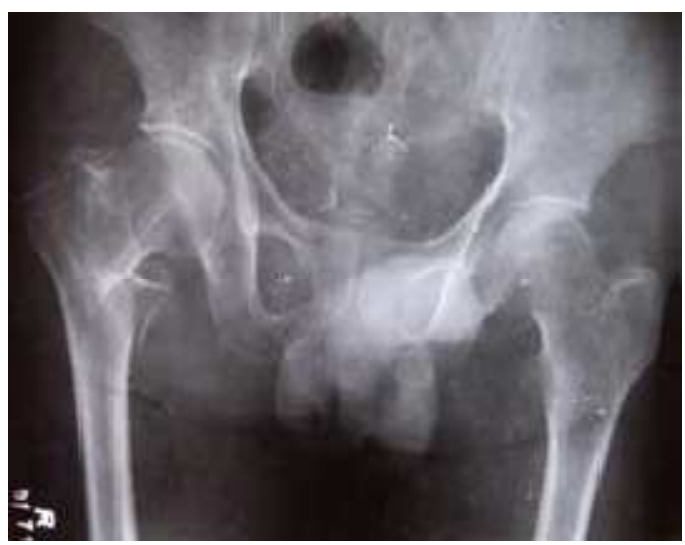

Fig 1: X-ray Pre-op

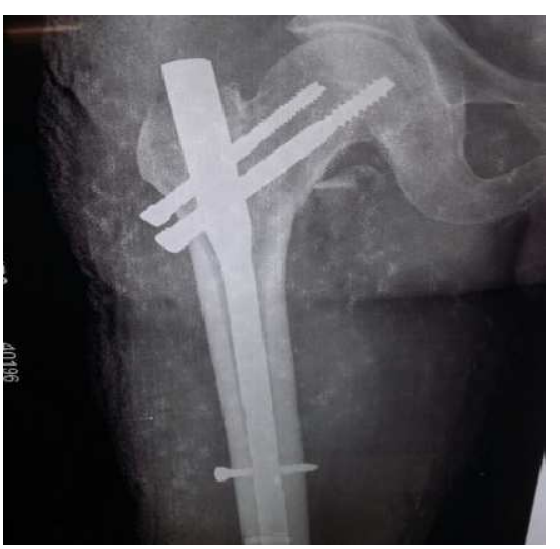

Fig 2: X-ray Post-op

\section{Results}

Out of 98 patients 32 (32.65\%) were females and $66(67.35 \%)$ were males. Age group ranged from 18 to 85 years. 40 patients $(40.81 \%)$ were between 60 to 70 yrs age group. $55(56.12 \%)$ patients had stable fracture and the rest $(43.87 \%)$ had unstable fracture. The functional outcome was observed. The excellent outcome was seen in $30(30.6 \%)$ patients, good outcome was found in $44(44.9 \%)$ patients, fair outcome was found in $14(14.2 \%)$ patients, and poor outcome was found in $10(10.2 \%)$ patients. In our study we found intraoperative complications in 13 cases. Loss of anatomical reduction occurred in two case during the procedure. In one cases it occurred at the time of proximal reaming and second during at the time of insertion of nail.

Table -1: Distribution of cases according to age

\begin{tabular}{|c|c|}
\hline Age in years & No. of patients $(\mathbf{\%}, \mathbf{n}=\mathbf{9 8})$ \\
\hline $18-30$ & $04(4.12 \%)$ \\
\hline $31-40$ & $10(10.2)$ \\
\hline $41-50$ & $09(9.18 \%)$ \\
\hline $51-60$ & $15(15.3 \%)$ \\
\hline $61-70$ & $40(40.81 . \%)$ \\
\hline $71-80$ & $16(16.32 \%)$ \\
\hline $81-90$ & $04(4.08 \%)$ \\
\hline Total & $\mathbf{9 8}(\mathbf{1 0 0} \%)$ \\
\hline
\end{tabular}

Table -2: Distribution of cases according to sex.

\begin{tabular}{|c|c|}
\hline Sex & No. of patients $(\mathbf{\%}, \mathbf{n = 9 8})$ \\
\hline Female & $32(32.65 \%)$ \\
\hline Male & $66(67.34 \%)$ \\
\hline Total & $\mathbf{9 8}(\mathbf{1 0 0 \%})$ \\
\hline
\end{tabular}

Table-3: Distribution of cases according to functional results in present study: (According modified Harris hip score)

\begin{tabular}{|c|c|c|}
\hline Clinical results & Total points & No. of Patients $(\mathbf{\%}, \mathbf{n}=\mathbf{9 8})$ \\
\hline Excellent & $81-100$ & $30(30.6 \%)$ \\
\hline Good & $61-80$ & $44(44.9 \%)$ \\
\hline Fair & $41-60$ & $14(14.2 \%)$ \\
\hline Poor & $<40$ & $10(10.2 \%)$ \\
\hline Total & & $\mathbf{9 8}(\mathbf{1 0 0} \%)$ \\
\hline
\end{tabular}




\section{Original Research Article}

Longitudinal fracture of femur above the tip of nail occurred in one case at the time of hammering. After that open reduction was done with encircle age of the fracture fragment. In one case we failed to put de-rotational screw because of jamming of the nail. This case showed varus deformity but with excellent outcome. Varus angulation occurred in 2 of our cases because of difficult reduction. It occurred in 2 of cases. We fixed the distal lock by free hand method in these cases. Mismatch leads to difficulty in placing proximal screws also.

This can also lead to missed distal locking, but in our study none of the case have missed distal locking. GT fracture occurred in two cases while inserting the nail. In early post-operative complication we found only one case of superficial wound infection. In our study we found no complication of implant failure, cutout, fracture shaft of femur below the tip of nail, avascular necrosis of head and non-union. In our study, we also didn't found any case of Z effect but we found one case of reverse $\mathrm{Z}$-effect. Absence of $\mathrm{Z}$ effect can be explained by proper positioning of screw, proper size and short duration of follow up.

\section{Discussion}

Intertrochanteric fractures represent a significant challenge to the trauma surgeon. Surgical fixation of unstable fractures of the proximal femur is often technically demanding and poor surgical technique may lead to failure of primary fixation $[8,9]$. The best treatment for these fractures remains controversial. DHS fixation is widely preferred but failure of fixation still occurs in up to $20 \%$ of cases [10].

Common causes of fixation failure include fracture instability, osteoporosis, lack of anatomic reduction, implant failure, and incorrect placement of the lag screw in the femoral head leading to cutting out of the screw [11]. Intramedullary implants inserted in a lessinvasive manner are better tolerated by the elderly. PFN has all the advantages like decreasing the moment arm, it can be performed by closed technique, preserving the fracture haematoma which is an important consideration in fracture healing. It also decreases blood loss, infection risk, minimizes soft tissue dissection and wound related complications [12].

The Proximal Femoral Nail (PFN) System offers some major biomechanical advantages [13]. Axial loading in A1 and A2 fractures leads to fracture impaction, whereas in A3 fractures such impaction doesn't occur and medial displacement of the distal fragment of the fracture is common due to the instability.

Proximal Femoral Nail for A3 type unstable fracture has superior results; PFN prevents the fractures of the femoral shaft by having a smaller distal shaft diameter which reduces stress concentration at the tip [14].

Due to its position close to the weight-bearing axis, the stress generated on the intramedullary implants is negligible. The PFN implant also acts as a buttress in preventing the mediatization of the shaft. The entry portal of the PFN through the trochanter limits the surgical insult to the tendinous hip abductor musculature, only unlike those nails which require entry through the pyriformis fossa $[15,16]$. The stabilizing and the compression screws of the PFN adequately compress the fracture, leaving between them a bone block for further revision if the need arise [14]. Domingo et al. [17] conducted a study on 295 patients for intertrochanteric fracture fixation with PFN and obtained overall results were comparable with those of other fracture systems, authors assert that technically surgery is not complex and numbers of recoded complications were acceptable.

The intraoperative variables and the systemic complications were similar to those encountered by other devices [18.19]. Uzun $M$ et al evaluated radiographic complications occurring after treatment of unstable intertrochanteric hip fractures with the Proximal Femoral Nail (PFN) and their effect on functional results on 35 patients [20].

The Harris hip score results were excellent in 11 patients $(31.4 \%)$, good in 15 patients $(42.9 \%)$, and fair in seven patients $(20 \%)$. The functional outcome after intramedullary PFN were also studied by Sachin S et al and Asad $\mathrm{K}$ et al The modified harris hip score was excellent in $24.4 \%$ and $28.6 \%$ respectively [21,22].

Good score was seen in $42.2 \%$ and $45.1 \%$ respectively along with a poor score seen in $13.3 \%$ and $9.9 \%$ of the patients respectively. The modified Harris score in the present study was comparable to above mentioned studies.

Considering the functional outcome of present study the proximal femora nail can be considered as a preferred choice for unstable intertrochanteric fractures. The modification of the PFN and careful surgical technique should reduce the complication rate in our study. 


\section{Original Research Article}

\section{Conclusion}

It can be concluded from the present study that though the Proximal Femoral Nailing is a technically demanding procedure requiring special instrumentation, it is a reliable implant giving consistent and reproducible results even in unstable intertrochanteric femur fractures at any age. It should be encouraged in fixation of all types of intertrochanteric fractures.

Funding: Nil, Conflict of interest: None Permission of IRB: Yes

\section{References}

1. Yadkikar SV, Yadkikar VS (2015) Prospective study of proximal femoral nail in management of trochanteric and subtrochanteric fractures of femur. Int $\mathbf{J}$ Biomed Adv Res 6(4): 349-54.

2. Gadegone WM, Salphale YS. Short proximal femoral nail fixation for trochanteric fractures. J Orthop Surg (Hong Kong). 2010 Apr; 18 (1): 39-44. DOI:10.1177/ 230949901001800109

3. Simmermacher RK, Bosch AM, Van der Werken C.The AO/ASIF-proximal femoral nail (PFN): a new device for the treatment of unstable proximal femoral fractures. Injury. 1999 Jun;30(5):327-32.

4. Sadowski C, Lübbeke A, Saudan M, et al. Treatment of reverse oblique and transverse intertrocha nteric fractures with use of an intramedullary nail or a 95 degrees screw-plate: a prospective, randomized study. J Bone Joint Surg Am. 2002 Mar; 84-A (3): $372-81$.

5. Elis J, Chechik O, Maman E, Steinberg EL. Expandable proximal femoral nails versus $95^{\circ}$ dynamic condylar screw-plates for the treatment of reverse oblique intertrochanteric fractures. Injury. 2012 Aug; 43 (8): 1313-7. DOI: 10. 1016/ j. injury. 2012. 05. 004

6. EVANS EM. The treatment of trochanteric fractures of the femur. J Bone Joint Surg Br. 1949 May;31B (2): 190-203.

7. Boldin C, Seibert FJ, Fankhauser Fet al. The proximal femoral nail (PFN)--a minimal invasive treatment of unstable proximal femoral fractures: a prospective study of 55 patients with a follow-up of 15 months. Acta Orthopaedica Scandinavica 74 (1): 53-8. March 2003. DOI: 10. 1080/ 000164703100 13662
8. Baumgaertner MR, Curtin SL, Lindskog DM, Keggi JM. The value of the tip-apex distance in predicting failure of fixation of peritrochanteric fractures of the hip. J Bone Joint Surg Am. 1995 Jul;77(7):1058-64.

9. Sierra RJ, Cabanela ME. Conversion of failed hip hemiarthroplasties after femoral neck fractures. Clin Orthop Relat Res. 2002 Jun;(399):129-39.

10. Simmermacher RK, Bosch AM, Van der Werken C. The AO/ASIF-proximal femoral nail (PFN): a new device for the treatment of unstable proximal femoral fractures. Injury. 1999 Jun;30(5):327-32.

11. Simpson AH, Varty K, Dodd CA. Sliding hip screws: modes of failure. Injury. 1989Jul; 20(4):227-31.

12. Kalliguddi S, Jawali V, Reneesh UP (2013) Proximal femoral nail in the mangement of peritrochanteric fractures femur and its functional outcome. Int J Res Pharm Biomed Sci 4(4): 1276-1286.

13. Korkmaz MF, Erdem MN, Disli Z, et al. Outcomes of trochanteric femoral fractures treated with proximal femoral nail: an analysis of 100 consecutive cases. Clin Interv Aging. 2014 Apr 3;9:569-74. DOI:10.2147/CIA. S59835

14. Gadegone WM, Salphale YS. Proximal femoral nail - an analysis of 100 cases of proximal femoral fractures with an average follow up of 1 year.Int Orthop. 2007 Jun; 31 (3):403-8. Epub 2006 Jun 21. DOI: 10.1007/ s00264- 006-0170-3

15. Menezes DF, Gamulin A, Noesberger B. Is the proximal femoral nail a suitable implant for treatment of all trochanteric fractures? Clin Orthop Relat Res. 2005 Oct; 439:221-7.

16. Ansari MoeinCM,Verhofstad MH, Bleys RL, van der Werken C. Soft tissue injury related to choice of entry point in antegrade femoral nailing: piriform fossa or greater trochanter tip. Injury. 2005 Nov;36(11):133742. DOI:10.1016/j.injury.2004.07.052

17. Domingo LJ, Cecilia D, Herrera A, Resines C. Trochanteric fractures treated with a proximal femoral nail. Int Orthop. 2001;25(5):298-301.

18. Simmermacher RK, Bosch AM, Van der Werken C. The AO/ASIF-proximal femoral nail (PFN): a new device for the treatment of unstable proximal femoral fractures. Injury. 1999 Jun; 30 (5): 327-32. 


\section{Original Research Article}

19. Simmermacher RK, Ljungqvist J, Bail H, et al. The new proximal femoral nail antirotation (PFNA) in daily practice: results of a multicentreclinical study. Injury. 2008 Aug; 39 (8): 932-9.DOI:10.1016/j.injury. 2008. 02.005

20. Uzun M, Ertürer E, Oztürk I, et al.[Long-term radiographic complications following treatment of unstable intertrochanteric femoral fractures with the proximal femoral nail and effects on functional results]. Acta Orthop Traumatol Turc. 2009; 43 (6): 457-63. DOI:10. 3944/ AOTT.2009.457
21. Kalliguddi S, Jawali V, Reneesh UP. Proximal femoral nail in the mangement of peritrochanteric fractures femur and its functional outcome. Int J Res Pharm Biomed Sci 2013;4(4): 1276-1286.

22. AsadK, Syed K,Muhammad K et al. Role of proximal femoral nail in treatment of unstable intertrochanteric fracture. Biomed J Sci \& Tech Res 20182 (1)1-5.

\section{How to cite this article?}

Khairnar A, Patil L. A study of functional outcome in intertrochanteric femur fractures treated by proximal femoral nailing. Int J Med Res Rev 2018; 6(06):335-340.doi:10.17511/ijmrr.2018.i06.07. 